\title{
Feedback na prática letiva: Uma oficina de formação de professores
}

\author{
Jesuína Fonsecai, Carolina Carvalhoii, Joseph \\ Conboy iii, Helena Salemaiv \& Maria Odete Valentev \\ Universidade de Lisboa, Portugal
}

\author{
Ana Paula Gamavi \\ Instituto Superior D. Afonso III, Portugal
}

\section{Edite Fiúzavii}

Universidade Lusófona de Humanidades e Tecnologias, Portugal

\begin{abstract}
Resumo
O uso de feedback em sala de aula pode promover a qualidade das relações professor-aluno e o envolvimento académico e desempenho dos alunos, apesar de nem sempre os professores o usarem da melhor forma. Neste artigo descreve-se o desenvolvimento e a avaliação de uma oficina projetada para melhorar os conhecimentos e as capacidades dos professores no uso de estratégias de feedback e a valorização destas. Doze professores participaram na oficina. Relatos e reflexões dos professores revelam que a participação na oficina potenciou maior sensibilização e uso mais adequado de estratégias de feedback. Uma oficina de longa duração, que integre objetivos específicos respeitantes a estratégias de feedback e sessões reflexivas intercaladas com trabalho de aplicação em sala de aula, pode promover o envolvimento, os conhecimentos e as competências dos participantes no uso dessas estratégias. Pode ainda resultar num maior envolvimento e aprendizagem por parte dos alunos desses professores.
\end{abstract}

Palavras-chave

Formação de professores; Feedback do professor; Estratégias e efeitos do feedback; Oficina

\section{Introdução}

O feedback do professor relativo ao desempenho e compreensão por parte do aluno pode constituir o aspeto prático mais importante da relação 
entre professores e alunos (Black \& Wiliam, 1998; Black, Harrison, Lee, Marshall, \& Wiliam, 2002). Além de influenciar a compreensão e o desempenho dos alunos (Kluger \& DeNisi, 1996, 1998; Salema, 2005; Valente, 1997; Zimmerman \& Schunk, 2001, 2007), o feedback do professor tem um papel fundamental no seu envolvimento com a escola (Carvalho et al., 2011; Conboy \& Fonseca, 2009; Fonseca, Valente, \& Conboy, 2011; Fonseca \& Conboy, 2006; Fredricks, Blumenfeld, \& Paris, 2004; Schussler, 2009; Veiga, 2009; Verkuyten \& Thijs, 2009). Afeta também a construção da identidade do aluno e as suas trajetórias académicas (Cornelius \& Herrenkohl, 2004). Especificamente, sendo uma componente da qualidade da relação que os professores desenvolvem com os seus alunos, o feedback, juntamente com diversos tipos de tarefas e atividades que os professores propõem, afetará os contextos de participação (Carvalho \& Solomon, 2012) e pode contribuir para reificar posições de identidade (Freire, Carvalho, Freire, Azevedo, \& Oliveira, 2009). Apesar da sua importância, largamente acentuada na literatura, alguns resultados de investigação apontam para um mau uso do feedback por parte do professor, na sua sala de aula (Valente, Conboy, \& Carvalho, 2009), e para uma consequente necessidade de desenvolvimento profissional de professores neste domínio.

\section{Feedback: evidências, estrutura e consequências}

O feedback ocorre após um comportamento, intervenção ou atitude e consiste na informação que recebemos sobre como estamos a sair-nos no esforço que desenvolvemos para alcançar um determinado objetivo (Wiggins, 2012). O feedback é sempre uma consequência da nossa atuação e a sua finalidade pedagógica é fornecer informações relacionadas com a tarefa ou processo de aprendizagem, a fim de melhorar o desempenho numa tarefa específica e/ou o entendimento de um determinado assunto (Sadler, 1989). De acordo com Hattie (2009), o feedback visa a redução das discrepâncias entre a compreensão e desempenho atuais, por um lado, e uma intenção ou objetivo de aprendizagem, por outro.

O feedback tem sido descrito por vários autores como tendo dimensões cognitivas, motivacionais e afetivas. Na sua dimensão cognitiva, pode ser entendido como a "informação fornecida por um agente (por exemplo, professores, colegas, livro, pais, o próprio, experiência) sobre 
aspetos do desempenho ou entendimento de outro agente" (Hattie \& Timperley, 2007, p. 81). Uma tal informação poderá ter impacto sobre a autorregulação da aprendizagem e sobre o desempenho do aluno (Kluger \& DeNisi, 1996, 1998; Salema, 2005; Valente, 1997; Zimmerman \& Schunk, 2001, 2007).

Brookhart (2008) descreve o feedback eficaz em termos de duas dimensões: a cognitiva e a motivacional. A dimensão cognitiva tem a ver com o fornecimento de informações necessárias aos alunos para poderem compreender "em que ponto se encontram na sua aprendizagem e o que têm de fazer a seguir" (p. 2); a dimensão motivacional diz respeito ao desenvolvimento, nos alunos, da "sensação de que têm controlo sobre sua própria aprendizagem" (p. 2).

A literatura indica igualmente que as estratégias de feedback são um fator relevante na promoção da relação entre professores e alunos, bem como no envolvimento académico destes e no seu desempenho e autorregulação de aprendizagens (Black et al., 2002; Black \& Wiliam, 1998; Hattie, 2009). Mas nem sempre assim acontece, como veremos a seguir.

Dweck (2006) teoriza que a natureza do feedback influencia o posicionamento motivacional dos alunos perante a situação de aprendizagem (mero desempenho vs mestria). Isto é, se o feedback do professor recompensa a velocidade, então será velocidade o que o aluno aprende a procurar; se o feedback mostra preferência por se obter a resposta certa, então os alunos irão esforçar-se por obter a resposta certa. Mas se o feedback está estruturado para reconhecer e compensar o esforço, a persistência e a aplicação de princípios, então os alunos irão aprender a trabalhar intensamente, a perseverar e a pensar.

Black e Wiliam (1998) sintetizaram os resultados de 250 estudos internacionais sobre a análise de desempenho em sala de aula e concluíram que há duas ações do professor que proporcionam um impacto mais sólido na aprendizagem do que qualquer outra inovação educacional já documentada: (a) envolver os alunos nessa análise; e (b) aumentar a quantidade de feedback descritivo, enquanto se diminui o feedback avaliativo. Hattie e Timperley (2007), usando uma abordagem de meta-análise, concluíram que se obtém magnitudes de efeito substancialmente mais elevadas para as estratégias de feedback do que para outras intervenções educativas mais 
típicas. Tais conclusões sobre a importância do feedback deram origem a um movimento que valoriza a avaliação para a aprendizagem, ao contrário da avaliação da aprendizagem ou da avaliação como aprendizagem (Black \& Wiliam, 1998; Wiggins, 2012).

Há um consenso geral de que o feedback deve ser dado a um nível que os alunos possam compreender (Orsmond, Merry, \& Reiling, 2005) e será mais eficaz na promoção da aprendizagem e facilitação da sua melhoria se for fornecido num ambiente propício, ao invés de ser oferecido como juízo de valor (Weaver, 2006). De acordo com Hattie (2009), o feedback pode ser direcionado para diferentes níveis: (a) a tarefa (o quão bem as tarefas são executadas); (b) o processamento da tarefa (o processo necessário para executar tarefas); (c) autorregulação (auto-monitorização das ações); e (d) o self (avaliações pessoais do aluno). Como tal, Hattie (2009) afirma que as estratégias a adotar por professores e alunos para reduzir discrepâncias de desempenho estarão em parte relacionadas com o nível a que o feedback tem lugar:

Se o feedback for direcionado para o nível adequado, poderá ajudar os alunos a compreender, realizar ou desenvolver estratégias eficazes para processar informações que se pretende sejam aprendidas. Para ser eficiente, o feedback deve ser claro, ter um propósito, ser significativo e compatível com o conhecimento prévio dos alunos, e deverá fornecer conexões lógicas (pp. 177178).

De acordo com Hattie (2009), o feedback é mais eficaz quando informa o aluno acerca do seu desempenho, quando o leva a concentrar-se em maneiras de melhorar esse desempenho, e ainda quando é fornecido em contextos que protejam a identidade e autoestima do aluno. Alguns estudos mostram também que os alunos apreciam e anseiam por um bom feedback, não apenas porque querem obter notas que Ihes permitam passar de ano, mas porque querem desenvolver as suas competências (Higgins, Hartley, \& Skelton, 2002; Orsmond et al., 2005; Valente et al., 2009).

\section{Quando o feedback não funciona ou funciona no sentido oposto ao desejado}

O feedback envolve uma dimensão afetiva de particular importância quando a informação transmitida pelo professor se centra no próprio aluno e 
não no desempenho ou compreensão. Este tipo de feedback, centrado nas características pessoais do aluno, pode algumas vezes ter resultados indesejáveis, entre eles aumentar o medo do fracasso. De facto, o feedback fornece informação que permite aos alunos fazer interpretações sobre si mesmos, sobre os outros e sobre a escola. No entanto, se a componente afetiva do feedback for negligenciada por um professor, os alunos poderão minimizar o seu esforço, tentando assim evitar riscos para si próprios na abordagem de tarefas desafiadoras (Black \& William, 1998). Isto acontece com maior frequência quando o feedback enfatiza aspectos do eu que podem influenciar, não somente as decisões que os estudantes tomam sobre a escola (Freire et al., 2009), mas também a maneira como se irão posicionar eles próprios na sua comunidade escolar (Hand, 2006; Holland, Lachicotte, Skinner, \& Cain, 1998).

Outros estudos têm mostrado que os alunos, por vezes, não respondem bem ao feedback do professor - ou por este feedback ser mal interpretado (Lea \& Street, 2000), ou por não ser valorizado (Hounsell, 1987), ou ainda por, tendo sido valorizado, não ser na prática utilizado (Ding, 1998). E mesmo quando tudo parece ter sido feito pedagogicamente de forma correta, o feedback pode não ter o efeito desejado sobre a aprendizagem dos alunos (Fritz, Morris, Bjork, Gelman, \& Wickens, 2000; McClellan, 2001).

Uma pesquisa recente realizada em Portugal apoia a afirmação de que muitas vezes os professores vêem o feedback como uma forma de fazer declarações sobre os alunos, e não sobre o seu ensino (Valente et al., 2009). Os autores descrevem métodos usados por professores do ensino secundário na apresentação de informações respeitantes à avaliação dos alunos, bem como as reações destes alunos ao receberem tais informações, e ainda como esta dinâmica pode afetar o envolvimento dos estudantes nas atividades escolares. Os resultados apoiaram a tese de Schussler (2009) de que as práticas de feedback que não motivem para a aquisição de conhecimentos e o desenvolvimento de capacidades, por parte do aluno, e não promovam uma relação professor-aluno baseada no respeito e na confiança podem ter um efeito adverso sobre o envolvimento académico dos estudantes.

Uma descoberta marcante do estudo descrito por Valente et al. (2009) foi a de que o mau uso de feedback do professor parece ser comum. Ao invés de ter o objetivo de se concentrar na tarefa e reduzir as discrepâncias de 
desempenho, o feedback era frequentemente centrado no próprio aluno e utilizado pelos professores para acusar, julgar e punir. Este tipo de feedback não será eficaz na promoção da aprendizagem e mostra, mais uma vez, como a dimensão afetiva do feedback pode funcionar como uma 'espada de dois gumes' (Kluger \& DeNisi, 1996). Com base nestes resultados, conclui-se que existe necessidade de se continuar a promover projetos de desenvolvimento profissional de professores em Portugal, a fim de se assegurar que as estratégias de feedback são usadas na sala de aula de um modo adequado e eficaz.

\section{O que os professores precisam saber sobre feedback}

A preparação adequada de professores no uso de feedback eficiente implica o desenvolvimento de competências adequadas para que possam ajudar os seus alunos a melhor compreenderem a distância a que se encontram dos objetivos de aprendizagem, não deixando nunca de proteger a autoestima destes.

Diversas abordagens ao feedback foram defendidas pelos vários autores referidos nos parágrafos anteriores. A fim de desenvolver um enquadramento teórico apropriado para o desenvolvimento profissional, consideramos o que essas abordagens têm em comum e, usando a morfologia de Brookhart (2008), relativa a Estratégias e Conteúdo, podemos resumir algumas características comuns do feedback.

As Estratégias de feedback podem ser descritas e avaliadas em termos de: (a) Timing (quando é dado o feedback e com que frequência); (b) Quantidade (quantidade de feedback dado); (c) Modo (oral, escrito, ou feedback visual/cinestésico); e (d) Audiência (individual, grupo, feedback em grupo-turma). O Conteúdo do feedback pode ser descrito e avaliado em termos de: (a) Enfoque (trabalho, processo, autorregulação); (b) Comparação (critério, norma, autorreferenciada); (c) Função/Valência (descrição, juízo de valor/valência positiva ou negativa); (d) Clareza/Especificidade; e (e) Tom (respeito pelo aluno, aluno como agente).

De modo a ser eficaz, o feedback de sala de aula deve ter características identificáveis que estão, em grande parte, sob o controlo parcial do professor. O feedback eficaz é apresentado o mais rapidamente 
possível após o facto (Timing) e é seletivo. Ou seja, os professores não devem tentar comentar todos os aspetos do desempenho dos alunos, mas sim focalizar os aspetos específicos que terão o maior efeito (Quantidade). 0 feedback pode ser eficaz, quer seja oral, escrito ou visual, quer seja dado individualmente ou em grupo. Os professores devem reconhecer que cada situação específica poderá levar a um diferente e preferencial Modo e também Audiência.

O Conteúdo do feedback eficaz pode ser descrito e avaliado de uma forma semelhante. Os professores têm de ter a capacidade de analisar e criticar as suas próprias práticas de feedback. Será que essas práticas tendem a enfatizar o trabalho do aluno, o processo cognitivo, ou questões de autorregulação (Enfoque)? Ao identificar discrepâncias entre metas e desempenho, fazem-no com base num critério de referência, numa norma, ou ainda com base no desempenho prévio do aluno (Comparação)? São os comentários dos professores de carácter descritivo ou crítico? São positivos ou negativos (Função/Valência)? Finalmente, a informação apresentada sobre as discrepâncias desempenho/meta é uma informação compreensível e acionável (Clareza/Especificidade)? E é sensível às relações de poder potencialmente desiguais na sala de aula e a preocupações com a autoestima do aluno (Tom)?

Estas características das estratégias e conteúdo de feedback não devem ser entendidas como dimensões isoladas e ortogonais. Estão intrinsecamente interligadas. Um programa de desenvolvimento profissional deve procurar preparar um professor para ser capaz de identificar opções de prática de sala de aula e seus efeitos potenciais. Esse professor irá promover a comunicação interativa e descritiva, em vez de uma comunicação crítica e de sentido único, e irá concentrar-se no trabalho do aluno e não no próprio aluno. Tal professor é franco e aberto na comunicação das discrepâncias metas/desempenho encontradas e, ao mesmo tempo, sensível a preocupações relativas à autoestima do aluno. Será um professor que contribui para um ambiente de abertura e de respeito mútuo que promove o controlo dos alunos sobre sua própria aprendizagem. 


\section{Como promover a aprendizagem sobre feedback por parte dos professores}

Ao pensar-se num programa de desenvolvimento profissional de professores, a preocupação central é a do potencial formativo do mesmo, designadamente a sua eficácia na consecução dos objetivos pretendidos - no caso específico do programa aqui descrito e avaliado, a alteração e melhoria de conhecimentos e competências dos professores no uso de feedback, bem como a alteração e melhoria dos seus sentimentos relativos a esse uso e, ainda, a aplicação efetiva de estratégias de feedback na prática letiva dos professores.

Alguns estudos internacionais indicam que o desempenho dos alunos está diretamente relacionado com o investimento e apoio colocados no desenvolvimento profissional dos professores (Jaquith, Mindich, Wei, \& Darling-Hammond, 2010) e que a qualidade do ensino está diretamente relacionada com a qualidade do desenvolvimento profissional que os professores recebem (Guskey \& Yoon, 2009). Lawless \& Pellegrino (2007) acreditam que um programa de desenvolvimento profissional de qualidade elevada tem de ter uma longa duração (incluindo tempo de contacto presencial e respetiva aplicação na sala de aula), envolver os professores em atividades relevantes para o seu contexto específico de sala de aula, promover a colaboração entre pares e a formação de uma comunidade e, finalmente, estar imbuído de uma visão claramente articulada do que se pretende em termos de desempenho do aluno. Outros autores recomendam uma estrutura semelhante para os programas de desenvolvimento profissional de professores: (a) ênfase em objetivos específicos; (b) integração entre teoria e prática; (c) implementação a longo termo (distribuída ao longo de um ano escolar ou mais); (d) aplicação à sala de aula; e (e) reflexão colaborativa entre pares (Dana, Campbell, \& Lunetta, 1997; Fonseca, 2002; Fonseca, Conboy, Macedo, \& Mestre, 2004; Hattie \& Timperley, 2007; Salema, 2005).

Um estudo conduzido em 2000 pelo National Center for Education Statistics, nos EUA, revelou que os professores percecionam o desenvolvimento profissional formal como não tendo efeito no seu ensino, a não ser que seja desenhado e planeado para interligar o que os professores aprendem com o que acontece realmente na sua sala de aula (Hodge, 2014). 
Adicionalmente, o desenvolvimento profissional tem de ser embebido no contexto educacional de sala de aula, isto é, tem de visar a melhoria da relação entre o ensino académico feito pelo professor e a motivação para aprender por parte dos alunos.

Para além da teorização que modela um programa de formação, o modo como se 'ensina' um professor ao longo desse programa tem de ser igualmente equacionado. Assim, de acordo com a literatura, uma oficina de formação sobre feedback deverá ser estruturada de modo a propor e discutir as linhas-mestras de todo o programa, facultar informação útil sobre os conceitos relevantes a serem tratados (no caso específico da nossa oficina, conceitos de feedback e outros que the estão associados) e promover um ambiente facilitador e de confiança. Deverá ainda proceder à identificação dos sentimentos e posicionamentos iniciais ('crenças') dos professores relativamente ao uso de feedback e relativamente à análise e observação do mesmo em sala de aula. E deverá partir desses posicionamentos evolvendo no sentido de os alterar e melhorar.

Partindo-se de uma postura de negação relativa à necessidade de mudança através da observação, como é esperado de grande parte dos professores, e através de atividades hands-on e/ou role-play em que o formador modele o uso de feedback, com observação feita por alguns participantes, e posterior reflexão colaborativa entre todos os presentes, os professores serão levados a confrontar os seus posicionamentos iniciais com o que na sessão experienciam. Assim mudam as as suas ideias e acabam por propor, eles próprios, atividades subsequentes de melhoria no uso de feedback, nas suas salas de aula, com observação por pares. Várias outras sessões de formação poderão seguir uma formulação semelhante, sempre no sentido de aprimorar e aprofundar conhecimentos e competências no uso de feedback e alterar sentimentos relativos a esse uso.

\section{A oficina de formação sobre feedback}

\section{Objetivo}

O objetivo deste artigo é descrever e avaliar uma oficina que procurou promover o desenvolvimento profissional do professor no uso de estratégias de feedback adequadas e eficientes. O estudo é de natureza qualitativa e 
descritiva e envolve uma análise das sessões presenciais da oficina e do trabalho autónomo dos participantes (aplicação em sala de aula dos conteúdos e objetivos das sessões). Os métodos específicos de recolha de dados incluíram a observação, relatórios escritos solicitados aos participantes e a reflexão conjunta do formador com os participantes durante as sessões da oficina.

\section{Método}

A organização, delineamento e implementação da oficina, como veículo de desenvolvimento profissional de professores, teve como objetivos a melhoria nos conhecimentos e capacidades dos participantes no que respeita ao uso de feedback adequado e eficiente, a promoção de sentimentos positivos em relação à importância de estratégias de feedback e, ainda, a aplicação efetiva de tais estratégias em sala de aula, com reflexão sobre as mesmas.

Integrada num projeto de investigação mais amplo, a oficina incluiu temas como: (a) Feedback do professor e envolvimento, identidade e trajetórias académicas do aluno; (b) Observação e análise de estratégias de feedback; (c) Estratégias de comunicação e processamento cognitivo; (d) Tipos e consequências de feedback num quadro de identidade e motivações do aluno; (e) Feedback verbal e não-verbal no trabalho de grupo colaborativo; (f) Feedback em contextos de resolução de problemas; (g) Conceções dos participantes sobre fatores da motivação escolar dos alunos; e (h) Avaliação da oficina de formação, expectativas e concretizações, dificuldades e sucessos.

As sessões de trabalho, facilitadas por dois formadores (ver secção "Procedimentos gerais para as sessões", mais adiante), incluíram a apresentação, discussão e, por vezes, a simulação de práticas de feedback, seguindo-se atividades de aplicação em grupos de trabalho (jogos, simulações, dramatizações e outros) e posterior reflexão sobre as mesmas. As duas últimas sessões de formação não tiveram esse formato - serviram de reflexão sobre as aprendizagens, sucessos e insucessos, frustrações ou motivações dos participantes, e de avaliação de todo o trabalho realizado. A penúltima foi uma sessão apenas de reflexão, com a intervenção individual de 
todos os professores. A última sessão incluiu, para além de reflexão de avaliação do trabalho e aprendizagens dos participantes e da própria oficina, o preenchimento de dois questionários de avaliação, um fornecido pelo Conselho Científico-Pedagógico da Formação Contínua e outro preparado pelos coordenadores da oficina, solicitando a opinião geral dos participantes sobre o programa de formação, sobre em que medida as suas expetativas haviam sido concretizadas e ainda sobre a sua disponibilidade para colaboração futura com os formadores.

As sessões presenciais ocorreram mensalmente. A seguir a cada sessão, os participantes realizaram trabalho autónomo nas suas turmas, com aplicação das aprendizagens respeitantes a essa sessão. Este trabalho foi acompanhado à distância pelos formadores. $O$ trabalho incluiu também uma reflexão por escrito que foi analisada pelos formadores.

$\mathrm{Na}$ primeira sessão, uma introdução teórica incluiu conceitos de diferentes tipos de feedback e suas consequências, bem como os conceitos relacionados de identidade estudantil, envolvimento dos alunos e trajetórias académicas. Os participantes foram informados de que havia sido preparada, para a oficina, uma plataforma web, o Moodle, a que teriam acesso permanente e que seria constantemente atualizada ao longo das várias sessões, através de afixação de textos científicos, descrição das sessões e outras informações úteis. O Moodle serviria também como plataforma de apoio aos professores, por parte dos formadores, durante o trabalho nãopresencial. No trabalho não-presencial para a primeira sessão, os participantes examinaram literatura relevante, bem como relatórios que apresentavam indicadores de boas práticas de feedback.

Nas cinco sessões seguintes, através de atividades práticas e em contextos específicos, conforme os temas tratados, os participantes experimentaram estratégias de feedback: primeiro exercitaram-nas como 'alunos'; em seguida, aplicaram-nas como 'professores'. Finalmente, refletiram sobre essas estratégias e seus efeitos. No trabalho autónomo, os professores conceberam, desenvolveram e implementaram estratégias de feedback para promover a aprendizagem dos alunos nas suas áreas curriculares específicas e escreveram relatos descritivos da aplicação e seus efeitos. Os formadores da oficina ajudaram os participantes na análise de feedback implementado nas suas aulas e ajudaram-nos no desenvolvimento 
de competências de investigação sobre as suas práticas de ensino (incluindo auto e heteroavaliação das suas convicções, formas de pensar e processos implementados), a fim de melhorar essas práticas e a própria reflexão sobre elas. Seguindo estes procedimentos, os professores resolveram alguns problemas surgidos na sua prática de ensino, elaborando também alguns materiais e atividades curriculares úteis para essa prática e que puderam partilhar.

\section{Estrutura, participantes e contexto}

O planeamento e a conceção da oficina de formação foram guiados por recomendações baseadas na literatura para a preparação deste tipo de ações para o desenvolvimento profissional do professor. Assim, como vimos acima, a estrutura prevê: (a) ênfase em objetivos específicos; (b) integração entre teoria e prática; (c) implementação de longo prazo (distribuída ao longo de um ano escolar); (d) aplicação e reflexão colaborativa por pares (Dana et al., 1997; Fonseca, 2002; Fonseca et al., 2004; Hattie \& Timperley, 2007; Salema, 2005); e ainda (e) interligação entre o que os professores aprendem e o que acontece realmente na sua sala de aula (Hodge, 2014).

A estrutura da oficina procurou igualmente ter em conta alguma outra literatura (e.g. Paakkari, Tynjäla, \& Kannas, 2001) onde se procura associar as conceções dos professores e as decisões tomadas na prática letiva para as aprendizagens dos alunos em sala de aula, tendo, no entanto, em conta que "a relação causal entre ambas é difícil de demonstrar" (Paakkari et al., 2001 , p. 705), atendendo aos diversos contextos educacionais que situam as práticas dos professores.

Doze professores de uma escola na área da grande Lisboa ofereceram-se para participar na oficina. Todos os professores tinham mais de cinco anos de experiência de ensino e provinham das áreas curriculares de Inglês, Geografia, Física e Química, História, Matemática, Economia e Português. Seis possuíam uma pós-graduação numa área de educação. Os alunos desses professores distribuíam-se por vários anos de escolaridade, do 7. ao $11 .^{\circ}$.

A oficina teve lugar nas instalações da escola, após o estabelecimento de um protocolo entre esta e o Instituto de Educação da Universidade de 
Lisboa. A escola fica situada numa comunidade socialmente carenciada, com elevada densidade populacional e famílias, em geral, de baixos rendimentos. A população escolar é caracterizada pela heterogeneidade cultural, incluindo estudantes portugueses, estudantes provenientes de outros países de língua portuguesa como Angola e Brasil, mas também alunos da Ucrânia, Moldávia, Roménia, Paquistão e Índia. Embora este multiculturalismo possa ter benefícios, levanta também algumas questões relacionais e de linguagem. Têm sido identificados nesta escola problemas relacionados com indisciplina e violência, altas taxas de retenção e desistência, e escasso envolvimento das famílias com a escola.

\section{Instrumentos de observação e análise}

O modelo de desenvolvimento profissional do professor utilizado assume a importância da reflexão sobre a prática docente em sala de aula. $O$ referencial teórico fornece áreas específicas para a reflexão. A fim de promover e facilitar essa reflexão, foi elaborada, pelos formadores, uma grelha de observação destinada à identificação e análise de feedback. A preparação da grelha incorporou ideais de Hattie (2009), Black e William (1998) e Wiggins (2012). A sua organização centra-se, no entanto, sobretudo nas quatro estratégias e cinco áreas de conteúdo do feedback introduzidas por Brookhart (2008). A grelha foi usada de forma flexível - houve diversas adaptações consoante os temas tratados -, tanto nos trabalhos de grupo de algumas das sessões presenciais, como no trabalho autónomo que os participantes realizaram nas suas salas de aula.

Apresenta-se na Tabela 1 a grelha mais amplamente utilizada. Nesta tabela são apresentadas as sete categorias mais tipicamente analisadas pelos professores nos seus relatórios (timing, modo, audiência, enfoque, tom, função/valência, clareza/especificidade), bem como uma breve descrição de cada uma delas. Não é nossa intenção quantificar, ou diferenciar, a importância atribuída a cada uma das categorias. Tal hierarquia teria pouco significado, dadas as diferentes áreas científicas dos professores e a natureza, não conhecida em pormenor, das atividades específicas de sala de aula que deram origem à identificação das categorias. 
Tabela 1 - Estratégias de feedback

\begin{tabular}{|c|c|}
\hline Estratégias & Descrição \\
\hline Timing & $\begin{array}{l}\text { - Fornece feedback imediato ou comentário com ligeiro atraso, para a } \\
\text { compreensão do aluno }\end{array}$ \\
\hline & $\begin{array}{l}\text { - Seleciona o melhor modo para a mensagem (oral, escrito, visual, cinestésico) } \\
\text { - Feedback interativo }\end{array}$ \\
\hline Audiência & - O feedback é individual?; ou o feedback é dado em grupo? \\
\hline Conteúdo & \\
\hline Enfoque & $\begin{array}{l}\text { - No trabalho; no processo que o aluno usou } \\
\text { - Na autorregulação do aluno }\end{array}$ \\
\hline Tom & $\begin{array}{l}\text { - Escolhe palavras que comunicam respeito e posicionam o aluno como agente } \\
\text { - Escolhe palavras ou atitudes que levam os alunos a pensar/pede elaboração }\end{array}$ \\
\hline Função/Valência & $\begin{array}{l}\text { - É descritivo, não julga } \\
\text { - As descrições negativas do trabalho são acompanhadas de sugestões } \\
\text { positivas, com vista à melhoria }\end{array}$ \\
\hline Clareza/Especificidade & $\begin{array}{l}\text { - Usa vocabulário e conceitos que o aluno vai entender } \\
\text { - Ajusta o grau de especificidade ao aluno e à tarefa }\end{array}$ \\
\hline
\end{tabular}

Pontualmente, foram ainda usadas mais duas grelhas adaptadas ao tipo de trabalho a ser executado, uma direcionada para o feedback não-verbal (utilizada numa das sessões presenciais) e outra para o trabalho de grupo na resolução de problemas (utilizada noutra das sessões presenciais). A primeira incidia sobre as competências de atendimento não-verbal do professor, demonstradas em termos de atenção e importância dadas às ações, mensagens e verbalizações do aluno, nomeadamente através da postura, contacto visual, espaço corporal, barreiras e igualdade/desigualdade de estatuto. A segunda integrava uma alternativa de classificação das dimensões do feedback, tendo ainda por base os trabalhos de Brookhart (2008), Hattie (2009) e Wiggins (2012). Considerava cinco dimensões: (1) timing (significado idêntico ao do item homónimo da grelha descrita na Tabela 1); (2) probabilidade de uso futuro (feedback é concreto, compreensível, acionável); (3) tangibilidade e transparência (feedback incide sobre aspetos relevantes, é suficiente para ajudar o aluno a continuar e promove a compreensão de relações entre ideias); (4) meta-referência (feedback compara o desempenho com a meta a alcançar; fornece alternativas para atingir a meta); e (5) consistência (feedback descreve o que foi feito e sugere formas de melhorar). 


\section{Procedimentos gerais para as sessões}

A oficina foi estruturada em oito sessões de três horas, uma sessão por mês a partir de outubro até ao final de maio. Havia sete formadores envolvidos na oficina. Dois dos formadores foram os coordenadores de todo o trabalho desenvolvido e são indicados neste artigo como os primeiros dois autores. Cada formador era responsável por uma sessão presencial e pela forma como se pretendia que fosse aplicada em sala de aula por parte dos participantes. Cada sessão foi orientada, segundo uma abordagem de team-teaching, por dois dos formadores de professores; um deles era o responsável por essa sessão específica e o outro era um dos coordenadores. A presença de pelo menos um dos coordenadores em cada sessão teve a finalidade de assegurar a continuidade e articulação entre todas as sessões. Para garantir a consistência entre os formadores, foram realizadas reuniões de reflexão colaborativa regulares com todos eles presentes.

Atividades em grupos de trabalho. A exploração de feedback através de atividades em grupo ilustrou os conceitos e temas abordados na introdução da sessão. Em algumas das sessões, por cada grupo de trabalho, foram designados um 'observador' e um 'professor'. Em outras sessões, o 'professor' era o próprio formador da sessão. O observador registava os comentários de feedback utilizados pelo designado 'professor' e também pelos participantes do grupo. No final das atividades de grupo, houve discussão nesses pequenos grupos, para identificar e avaliar as estratégias de feedback que foram úteis para a progressão da atividade. Houve também uma discussão global, com todos os participantes, sobre as competências reveladas pelas técnicas de observação e sobre a sua eficiência.

Trabalho não-presencial atribuído. Após as atividades em grupo e discussão, era introduzido o trabalho a efetuar entre sessões - a aplicação, na sala de aula, do que tinha sido aprendido em cada uma das sessões. Os participantes foram convidados a desenvolver estratégias de feedback no conteúdo das suas áreas científicas e a implementar essas estratégias na sala de aula, bem como a analisar as práticas resultantes. Previamente à sessão presencial seguinte, os professores entregavam um relatório escrito 
com as suas auto e heterorreflexões respeitantes às práticas de feedback. Quando havia dúvidas ou comentários ao trabalho não-presencial, dedicavase algum tempo da sessão a essas questões. Na penúltima sessão, o trabalho autónomo dos professores teve um cariz diferente: pediu-se aos participantes para entrevistarem dois dos seus alunos com o objetivo de perceberem se eles tinham sentido ou detetado algumas diferenças nas atividades de sala de aula ou na forma como o professor comunicava com eles e qual a sua reação a essas diferenças, quando as havia. Os professores prepararam os guiões das entrevistas, transcreveram-nas e fizeram uma análise das respostas, que apresentaram na forma de relatório.

\section{Relatório final e autoanálise}

No final do ano letivo, tal como tinha sido informado nas primeiras sessões da oficina, os participantes foram solicitados a apresentar um relatório final sobre o seu desenvolvimento profissional em termos de implementação de estratégias de feedback. No relatório deveriam identificar os seus principais desafios e dificuldades na transferência do conhecimento para a sala de aula e as soluções encontradas para superar essas dificuldades. O relatório final também pedia aos professores para realizarem a autoavaliação do trabalho que desenvolveram ao longo dos oito meses em que decorreu o programa de formação e do impacto que os seus alunos haviam detetado nas suas ações letivas.

\section{Avaliação da oficina de formação}

A avaliação da oficina foi feita com base nas seguintes fontes de informação: (a) relatos escritos descritivos do trabalho não-presencial respeitante a cada uma das sessões presenciais; (b) relatório final escrito; (c) reflexões orais, especialmente nas duas últimas sessões presenciais; e (d) respostas aos dois questionários preenchidos na última sessão (um oficial, do serviço de creditação da formação contínua, para avaliação da oficina; e um interno, elaborado pelos coordenadores do programa de formação, sobre perspetivas respeitantes ao trabalho desenvolvido e planos de trabalho futuro).

As reflexões orais e as respostas aos dois questionários da última sessão presencial serão analisadas na secção "Discussão". Nos Relatos do 
Trabalho Não-Presencial, que constituíram também um dos elementos da avaliação dos participantes, os professores descreveram e analisaram a implementação do feedback em sala de aula, tendo como uma importante referência as grelhas observacionais desenvolvidas e utilizadas na oficina. Apresentamos a seguir alguns exemplos de como os professores, nos Relatos do Trabalho Não-Presencial ao longo do ano, descreveram o uso de estratégias de feedback e como entenderam a importância e os efeitos sobre os alunos de tais estratégias. Cada citação diz respeito a um professor diferente (no fim de cada uma, apresentamos a classificação de acordo com as categorias na Tabela 1).

(...) através do feedback individual aos alunos que trabalham em grupos, tomei consciência de que se trata de uma forma eficiente de feedback e acompanhamento destes alunos, embora isso me dê um pouco de frustração por não ser capaz de atender a todos os alunos que precisam de ajuda num determinado momento. [Audiência]

(...) na minha aula sobre diferenças culturais, perante atitudes xenófobas de alguns alunos, confrontei essas atitudes (feedback, NA) e envolvi todos os alunos numa atividade em que eles tinham que representar a situação de discriminação (feedback, NA), o que ajudou os alunos a melhorar as suas competências de cidadania. [Enfoque]

Eu não julguei negativamente as ideias do aluno... e o resultado foi positivo. [Função e Valência]

Um aluno disse-me, na minha aula de Inglês, que não era capaz de escrever em inglês. Perguntei-lhe por que seria. $O$ estudante pensou sobre as suas dificuldades e identificou, como razões, o vocabulário fraco e a dificuldade em conjugar os verbos. [Tom]

Durante a aula de Física e Química, usei vocabulário simplificado para uma melhor compreensão de conceitos por parte dos alunos e só mais tarde é que apresentei a terminologia científica. [Clareza e Especificidade]

Transcrevemos agora alguns exemplos de comentários provindos do trabalho autónomo dos professores, respeitantes à análise das respostas das entrevistas aos alunos. Novamente, as citações correspondem a diferentes professores e, na sua maioria, estes são distintos daqueles cujas citações incluímos acima.

Algo que me surpreendeu durante as entrevistas foi verificar que o feedback mais importante para estes alunos é o facto de o professor acreditar que eles 
conseguem ter sucesso: "A professora de Português diz que todos conseguem, $e$ este é um bom método porque leva a que os alunos acreditem que conseguem". Assim, constata-se que as crenças dos professores são muito influenciadoras para as expectativas que os alunos têm de si próprios, ou seja as trajetórias dos alunos podem ser marcadas, negativamente ou positivamente, a partir do posicionamento que o professor tem perante os seus alunos.

Muitos dos alunos que desistem são fruto de situações, em sala de aula, onde o professor não consegue dar uma resposta capaz, que vá ao encontro da questão que o aluno coloca. Cada aluno é um potencial que é necessário explorar e, para isso, são necessárias algumas condições, nomeadamente proporcionar feedback eficaz de acordo com as necessidades do aluno, e não de acordo com o que por vezes damos.

Há professores que ajudam mais aqueles de quem gostam do que aqueles que têm mais dificuldades.

O aluno A referiu, no seu discurso, que apesar de contar com a ajuda da mãe e dos colegas, a ajuda mais significativa para si, ao longo do ano, tinha sido dada pelos professores de apoio, pois sempre que tinha uma dúvida os professores davam feedback imediato, o que é bastante compreensível. Já o aluno B, referiu que a escola, em geral, era o local ideal para esclarecer as suas dúvidas, mas que a Internet era fundamental para si, embora com as limitações associadas.

Nas reflexões escritas no Relatório Final, alguns comentários dos participantes revelam que, através da sua participação na oficina, os professores desenvolveram, não só competências, mas também sentimentos positivos em relação ao uso das estratégias de feedback como instrumento para melhorar o envolvimento, motivação, autoconfiança e capacidades de pensamento e autorregulação dos seus alunos. Alguns professores também reiteraram a importância do feedback dos alunos para ajudar os professores a repensar as suas estratégias de ensino e os auxiliar na resolução de problemas do dia a dia. Uma ilustração desses efeitos pode ser dada pelos seguintes comentários fornecidos por alguns dos professores (deve notar-se que se procurou abranger, com estas e as outras citações, todos os doze professores):

Eu usei feedback oral em situações de trabalho de grupo e feedback escrito para o trabalho individual escrito. Isto parece funcionar bem em termos de ajudar os alunos a refletir sobre o seu trabalho. [Modo] 
O feedback oral que dei foi sempre interativo - o aluno e eu conversámos sobre o seu trabalho e sobre como eu poderia ajudá-lo a 'descobrir' as suas competências. [Modo]

Eu tinha como objetivo orientar os alunos para a sua autorregulação, fazendoos compreender que eles são os agentes da sua própria aprendizagem. Os alunos foram incentivados a pensar e refletir e avaliar a sua própria aprendizagem. [Enfoque]

Quando entreguei os testes, dei aos alunos o seu próprio teste, informando-os sobre a pontuação para cada questão. Pedi-lhes para identificarem os erros que tinham cometido em cada questão com base na pontuação que tinham obtido. [Tom]

Usar feedback imediato em casos de respostas erradas e feedback diferido para as situações de competências de processo resultará na motivação dos alunos e seu envolvimento. [Timing]

Quando notei uma conceção alternativa na argumentação do aluno, confrontei os argumentos com contra exemplos, a fim de conduzir o aluno a conceções mais rigorosas e científicas. [Função e Valência]

Para o Relatório Final, tínhamos pedido também aos participantes as suas reflexões pessoais sobre a oficina em termos do contributo que teve no seu desenvolvimento profissional. Seguem-se alguns comentários de quatro dos participantes:

Esta formação permitiu-me tomar consciência de algumas práticas, em termos de feedback, que eu já uso ao longo dos anos, sendo algumas positivas e outras que devem ser colocadas de lado. Sei que esta formação, só por si, não elimina, por artes de magia, os aspetos menos positivos desta prática, mas contribuiu para um olhar mais atento sobre eles.

Esta formação sobre a comunicação de feedback em sala de aula foi extremamente útil para a minha prática futura, uma vez que me permitiu reconhecer tipos e conteúdos de feedback e a sua importância na trajetória académica dos alunos. Acredito que o conhecimento que adquiri neste programa de formação é importante em termos do meu desempenho profissional, uma vez que me permite reconhecer formas de agir que vão ajudar o aluno a aprender a aprender, contribuindo para o seu sucesso.

Numa profissão em que a comunicação desempenha um papel tão importante, desenvolver e refinar o tipo de resposta (feedback) é fundamental para melhorar a qualidade da educação. Também estou mais ciente de alguns detalhes do que estava no início do workshop, o que é positivo para a compreensão e melhoria da minha abordagem com os alunos em sala de aula. 


\begin{abstract}
Adquiri ferramentas que irão facilitar a minha abordagem com estudantes e disciplinas curriculares; fiquei mais sensibilizada para adequadas formas de agir tendo em vista motivar e orientar os alunos através do uso de vários tipos de feedback. Tenho refletido sobre o impacto que as minhas atitudes verbais e não-verbais podem ter sobre os alunos.

(...) esta ação veio confirmar a sua importância em termos de conhecimento e de partilha, já que estes foram de grande importância para a docente e para a escola, pois o recurso a estratégias de feedback levou-nos a refletir sobre as práticas de ensino e, em conjunto, com a autorregulação das aprendizagens, alterou-se a planificação e as atividades na sala de aula.
\end{abstract}

\title{
Discussão e conclusões
}

A análise dos resultados do nosso programa de desenvolvimento profissional de professores, estruturado como uma oficina de formação, revelou que o programa cumpriu objetivos importantes relativamente aos professores participantes e, na opinião destes, também em relação aos seus alunos. Os professores desenvolveram conhecimentos e capacidades no uso e análise de estratégias de feedback, bem como melhoraram as suas atitudes relativamente ao uso dessas estratégias.

Observações provenientes das várias fontes de análise mostraram que o uso informado de estratégias de feedback influenciou a compreensão e o desempenho de alguns dos alunos dos professores participantes na oficina, na linha do que afirmaram vários autores (Kluger \& DeNisi, 1998; Salema, 2005; Valente, 1997; Zimmerman \& Schunk, 2007). Mostraram igualmente os efeitos positivos sobre o envolvimento dos alunos com a escola (Carvalho et al., 2011; Conboy \& Fonseca, 2009; Fonseca \& Conboy, 2006; Fredricks et al., 2004; Schussler, 2009; Verkuyten \& Thijs, 2009) e a importância do feedback do professor na qualidade da relação entre professores e alunos (Black \& Wiliam, 1998; Black et al., 2002).

As observações apoiam ainda a noção, introduzida por vários autores, de que os efeitos do feedback se manifestam em diversas dimensões, incluindo a cognitiva, a afetiva e a motivacional (Brookhart, 2008; Dweck, 2006; Hattie, 2009; Hattie \& Timperley, 2007). Do mesmo modo, encontrámos concordância entre os nossos resultados e a literatura em termos dos efeitos na autorregulação da aprendizagem e desempenho do aluno como agente recetor (Kluger \& DeNisi, 1996, 1998; Salema, 2005; Valente, 1997; Zimmerman \& Schunk, 2001, 2007). 
Das nove categorias de estratégias e conteúdos propostas por Brookhart (2008), encontrámos aplicação prática para sete. Nem a estratégia quantidade nem o conteúdo comparação foram validados pelos professores participantes nas suas citações e reflexões.

O nosso programa de desenvolvimento profissional não permitiu tirar conclusões sobre os efeitos de feedback na construção da identidade do aluno, nem das suas trajetórias académicas a longo prazo. Cornelius e Herrenkohl (2004) fazem afirmações nesse âmbito, mas uma constatação destes efeitos exigiria uma análise num período mais alargado.

É indispensável levar a cabo uma formação de professores que permita assegurar que são utilizadas, em sala de aula, estratégias de feedback adequadas e eficientes. Tais programas de formação de professores devem, de acordo com Brookhart (2008) e Carvalho e Solomon (2012), centrar-se em competências para desenvolver e implementar atividades e estratégias letivas que visem ajudar os alunos a ser reflexivos, concentrados e interessados em explorar a sua própria compreensão dos conteúdos da disciplina.

Segundo os professores, a oficina de formação ajudou-os a estarem mais atentos às características únicas de um determinado aluno e ao contexto de aprendizagem em que este está inserido, o que os levou, dessa forma, a adotar estratégias de feedback adequadas, conforme previsto no trabalho de Opfer e Pedder (2011).

Nas duas últimas sessões da oficina de desenvolvimento profissional descrita neste artigo, através de debates gerais e de respostas escritas a dois questionários de avaliação da oficina, os professores mostraram o seu apreço pelo facto de terem tido a oportunidade de trabalhar em equipa e de observar colegas e ser observados por eles, bem como de refletir de forma colaborativa sobre as suas competências na utilização de estratégias de feedback. Este último comentário revelou uma mudança substancial de atitude em relação a terem observadores do seu desempenho em sala de aula, pois que no início do programa tinha havido unânime resistência a tal observação.

No entanto, alguns participantes também indicaram, quer na reflexão oral, quer nas respostas ao questionário preparado pelos coordenadores, que já usavam estratégias de feedback antes da sua participação na oficina, 
embora de uma forma muito menos cuidadosa, sistemática e intencional. Alguns afirmaram que antes da participação na oficina não refletiam muito sobre as suas estratégias de feedback.

No geral, alguns comentários dos participantes incluídos nas respostas aos questionários revelam que, através da sua participação na oficina, os professores desenvolveram não só competências, mas também sentimentos positivos em relação ao uso das estratégias de feedback como instrumento para melhorar o envolvimento, a motivação, a autoconfiança e as competências de autorregulação dos seus alunos.

Os coordenadores do programa, responsáveis também pela última sessão, inquiriram os participantes sobre quais os aspetos da oficina que poderiam ser melhorados. Os professores declararam que o trabalho nãopresencial foi demasiado para o tempo que tinham disponível, por entre as suas responsabilidades escolares numerosas. Alguns deles indicaram que as sessões presenciais poderiam ter sido mais práticas, com mais exemplos dos conceitos focados e com mais partilha de experiências e de dificuldades e sucessos na elaboração do trabalho não-presencial. Estas sugestões foram igualmente indicadas num dos questionários aplicados na última sessão de formação.

Quando se Ihes perguntou sobre o seu interesse e disponibilidade para colaborar com os formadores no ano letivo seguinte, para aplicação e avaliação dos efeitos do feedback sobre os alunos, $50 \%$ dos participantes disseram que iriam fazê-lo se as condições na escola o permitissem. Estas respostas foram consistentes com as dadas por escrito.

Considerando as observações e sugestões feitas pelos participantes, sugerimos que atividades futuras de formação de professores relacionadas com a utilização de feedback nas suas práticas letivas devam sempre procurar uma profunda articulação entre todas as sessões do programa e um equilíbrio entre as abordagens mais teóricas e as mais práticas. Especificamente, em cada sessão deve haver uma alargada discussão sobre o trabalho não-presencial realizado. Além disso, os professores devem ter a possibilidade de trabalhar de forma colaborativa no desenvolvimento, implementação e análise das suas atividades em sala de aula. Um uso mais amplo de simulações de situações reais de sala de aula melhorará o conhecimento do professor sobre as estratégias de feedback mais úteis para 
cada aluno, tarefas específicas a realizar por este e organização de sala de aula que se pretende. No planeamento de programas futuros, é preciso também ter em mente que, embora o trabalho não-presencial solicitado deva encorajar os participantes a pesquisar e refletir profundamente sobre as suas práticas de feedback, é igualmente relevante e imprescindível que este trabalho seja possível no contexto de horários tão preenchidos quanto eram os que os participantes tinham no período em que decorreu a oficina.

A literatura científica em educação tem permitido desenvolver uma série de princípios úteis para a descrição de contextos e resultados educacionais, nomeadamente a associação entre a natureza do feedback dado pelos professores e o envolvimento e desempenho dos alunos. De forma consistente com a literatura, os resultados do nosso programa de formação indicam que as estratégias de feedback podem ser um fator relevante na promoção da relação em sala de aula, bem como na promoção do envolvimento, desempenho e autorregulação dos alunos. O impacto da oficina, observado qualitativamente, confirma a necessidade de uma formação de professores que vise a implementação de um feedback adequado pelos mesmos.

Estamos de acordo com Hattie (2009) ao sugerir pesquisas futuras que enfatizem esta importante área de estudo e importante área do ensino e desenvolvimento profissional de professores. Também é necessário estudar os programas de desenvolvimento profissional, a fim de identificar as características que os tornam bem sucedidos no cumprimento dos objetivos. Nas palavras de Williams e Ryan (2013), a investigação deve procurar estar mais preocupada em compreender como as coisas funcionam e menos com o que funciona. Contudo, estudos relativos à promoção de estratégias de feedback eficientes em sala de aula são escassos.

O nosso estudo identificou algumas características potencialmente relevantes: (a) a oficina focou objetivos específicos de desenvolvimento de conhecimento sobre feedback e adoção de adequadas estratégias de feedback por parte dos participantes; (b) foi implementado ao longo de um período de tempo prolongado; (c) integrou teoria e prática e envolveu sessões presenciais de grupo entremeadas com trabalho individual de aplicação em sala de aula; e (d) enfatizou a reflexão colaborativa entre professores. Um programa assim estruturado parece ter facilitado o desenvolvimento 
profissional dos professores, capacitando-os a usar estratégias de feedback de forma adequada e eficiente.

A oficina estruturada deste modo resultou na alteração do uso de feedback pelos professores em sala de aula e numa maior clarificação sobre as dinâmicas associadas. A participação nas sessões e a aplicação em sala de aula promoveram o envolvimento, conhecimentos e competências dos professores relativamente ao uso de adequadas estratégias de feedback. Uma grande parte dos professores participantes observou igualmente um maior envolvimento, participação ativa e aprendizagem por parte dos seus alunos.

\section{Nota}

Este trabalho foi financiado pela Fundação para a Ciência e Tecnologia (PTDC/CPE-PEC/121238/2010) e teve o apoio da UIDEF - Unidade de Investigação e Desenvolvimento em Educação e Formação, Instituto de Educação, Universidade de Lisboa. Agradecemos a todos os professores participantes o seu envolvimento, motivação e interesse. Também estamos muito gratos à administração da escola, por nos ter facilitado a participação dos seus professores nesta atividade de formação e também por nos ter facultado todas as condições logísticas. Estamos especialmente gratos ao nosso Bolseiro de Investigação, João Santos, pela sua ajuda no projeto.

\section{Referências}

Black, P., \& Wiliam, D. (1998). Inside the black box: Raising standards through classroom assessment. London: School of Education, King's College.

Black, P., Harrison, C., Lee, C., Marshall, B., \& Wiliam, D. (2002). Working inside the black box: Assessment for learning in the classroom. London: GL Assessment.

Brookhart, S. (2008). How to give effective feedback to your students. Alexandria, VA: Association for Supervision and Curriculum Development.

Carvalho, C., \& Solomon, Y. (2012). Supporting statistical literacy: What do culturally relevant/realistic tasks show us about the nature of pupil engagement with statistics? International Journal of Educational Research, 55, 57-65.

Carvalho, C., Freire, S., Conboy, J., Baptista, M., Freire, A., Azevedo, M., \& Oliveira, T. (2011). Student perceptions of secondary science teachers' practices following curricular change. Journal of Turkish Science Education, 8(1), 29-41. 
Conboy, J., \& Fonseca, J. (2009). Student generated recommendations for enhancing success in secondary science and mathematics in Portugal. Eurasia Journal of Mathematics, Science, and Technology Education, 5(1), 3-14.

Cornelius, L. L., \& Herrenkohl, L. R. (2004). Power in the classroom: How the classroom environment shapes students' relationships with each other and with concepts. Cognition and Instruction, 22(4), 467-498.

Dana, T., Campbell, L., \& Lunetta, V. (1997). Theoretical bases for reform of science teacher education. The Elementary School Journal, 97(4), 419-432.

Ding, L. (1998, September). Revisiting assessment and learning: Implications of students' perspectives on assessment feedback. Paper presented at the Scottish Educational Research Association Annual Conference, Dundee, Scotland.

Dweck, C. (2006). Mindset: The new psychology of success. New York: Random House.

Fonseca, J. (2002). A natureza de uma disciplina de didáctica: O caso específico da didáctica das ciências. Revista de Educação, 11(1), 61-77.

Fonseca, J., \& Conboy, J. (2006). Secondary student perceptions of factors affecting failure in science in Portugal. Eurasia Journal of Mathematics, Science and Technology Education, 2(2), 82-95.

Fonseca, J., Conboy, J., Macedo, M., \& Mestre, N. (2004). Pre-service science methods: The Girafe \& Co. model. Lusíada - Psicologia, 1(2), 5-24.

Fonseca, J., Valente, M., \& Conboy, J. (2011). Student characteristics and student science performance: Portugal in cross-national comparison. Procedia Social and Behavioral Sciences, 12, 322-329.

Fredricks, J. A., Blumenfeld, P. C., \& Paris, A. (2004). School engagement: Potential of the concept, state of the evidence. Review of Educational Research, 74, 59-109.

Freire, S., Carvalho, C., Freire, A., Azevedo, M., \& Oliveira, T. (2009). Identity construction through schooling: Listening to students' voice. European Educational Research Journal, 8(1), 80-88.

Fritz, C. O., Morris, P. E., Bjork, R. A., Gelman, R., \& Wickens, T. D. (2000). When further learning fails: Stability and change following repeated presentation of text. British Journal of Psychology, 92, 492-511.

Guskey, T., \& Yoon, K. (2009). What works in professional development? Phi Delta Kappan, 90 (7), 495-500.

Hand, V. (2006). Operationalizing culture and identity in ways to capture the negotiation of participation across communities. Human Development, 49, 36-41.

Hattie, J. (2009). Visible learning: A synthesis of over 800 meta-analyses relating to achievement. New York: Routledge.

Hattie, J., \& Timperley, H. (2007). The power of feedback. Review of Educational Research, 77(1), 81-112.

Higgins, R., Hartley, P., \& Skelton, A. (2002). The conscientious consumer: Reconsidering the role of assessment feedback in student learning. Studies in Higher Education, 27, 53-64. 
Hodge, E. (2014). Classroom-based professional development training program. Professional Development in Education, 41 (2), 316-320.

Holland, D., Lachicotte, W., Skinner, D., \& Cain, C. (1998). Identity and agency in cultural worlds. Cambridge: Harvard University Press.

Hounsell, D. (1987). Essay writing and the quality of feedback. In J. T. E. Richardson, M. W. Eysenck, \& D. W. Piper (Eds.), Student learning: Research in education and cognitive psychology (pp. 109-119). Milton Keynes, UK: Open University Press.

Jaquith, A., Mindich, D., Wei, R., \& Darling-Hammond, L. (2010). Teacher professional learning in the United States: Case studies of state policies and strategies. Oxford, OH: Learning Forward. Disponível em http://learningforward.org/docs/ pdf/2010phase3technicalreport.pdf?sfvrsn=0

Kluger, A. N., \& DeNisi, A. (1996). The effects of feedback interventions on performance: Historical review, a meta-analysis and a preliminary feedback intervention theory. Psychological Bulletin, 119, 254-284.

Kluger, A. N., \& DeNisi, A. (1998). Feedback interventions: Towards the understanding of a double-edged sword. Current Directions in Psychological Science, 7(3), 6772.

Lawless, K., \& Pellegrino, J. (2007). Professional development in integrating technology into teaching and learning: Knowns, unknowns, and ways to pursue better questions and answers. Review of Educational Research, 77 (4), 575-614.

Lea, M., \& Street, B. (2000). Student writing and staff feedback in higher education: An academic literacies approach. In M. Lea \& B. Stierer (Eds.), Student writing in higher education: New contexts (pp. 32-46). Buckingham, UK: Open University Press.

McClellan, E. (2001). Assessment for learning: The different perceptions of tutors and students. Assessment and Evaluation in Higher Education, 26, 307-318.

Opfer, V. D., \& Pedder, D. (2011). Conceptualizing teacher professional learning. Review of Educational Research, 81(3), 376-407.

Orsmond, P., Merry, S., \& Reiling, K. (2005). Biology students' utilization of tutors' formative feedback: A qualitative interview study. Assessment and Evaluation in Higher Education, 30, 369-386.

Paakkari, L., Tynjäla, L., \& Kannas, L. (2011). Critical aspects of student teachers' conceptions of learning. Learning and Instruction, 21(6), 705-714.

Sadler, D.R. (1989). Formative assessment and the design of instructional systems. Instructional Science, 18, 119-144.

Salema, M. H. (2005). Teacher and trainer training in education for democratic citizenship: Competencies, methods and processes. Journal of Social Science Education, 4(3), 39-49.

Schussler, D. (2009). Beyond content: How teachers manage classrooms to facilitate intellectual engagement for disengaged students. Theory into Practice, 48(2), 114-121.

Valente, M. O. (1997). Projecto Dianoia: Learning to think. In J. H. M. Hamers \& M. T. Overtoom, (Eds.), Teaching thinking in Europe (pp. 282-287). Utrecht: Sardes. 
Valente, M.O., Carvalho, C., \& Conboy, J. (2009, September). Student voices on how engagement is influenced by teacher's communication of evaluation results. Paper presented at the European Conference on Educational Research, Vienna.

Veiga, F. H. (2009). Underachievers, overachievers and student's self-concept. International Journal of Developmental and Educational Psychology, 2, 299-306.

Verkuyten, J., \& Thijs, M. (2009). Students' anticipated situational engagement: The roles of teacher behavior, personal engagement, and gender. The Journal of Genetic Psychology, 170(3), 268-286.

Weaver, M. R. (2006). Do students value feedback? Student perceptions of tutors' written responses. Assessment and Evaluation in Higher Education, 31, 379394.

Wiggins, G. (2012). Seven keys to effective feedback. Feedback for learning, 70(1), 1016.

Williams, J. \& Ryan, J. (2013). Research, policy and professional development: Designing hybrid activities in third spaces. In V. Farnsworth \& Y. Solomon (Eds), Reframing educational research, resisting the "what works" agenda (pp. 200213). London: Routledge.

Zimmerman, B.J., \& Schunk, D. (2001). Self-regulated learning and academic achievement: Theoretical perspectives. Mahwah, NJ: Lawrence Erlbaum.

Zimmerman, B.J., \& Schunk, D. (2007). Motivation and self-regulated learning: Theory, research and applications. Mahwah, NJ: Lawrence Erlbaum. 
FEEDBACK IN TEACHING PRACTICE: A WORKSHOP FOR TEACHERS

Abstract

The use of feedback in the classroom can promote the quality of teacherstudent relationships, student academic involvement and achievement, even though teachers may not always use it in the best way. In this article we describe the development and evaluation of a workshop designed to enhance teacher knowledge and skills in the use of feedback strategies. Twelve teachers participated in the workshop. Reports and reflections of teachers reveal that participation in the workshop potentiated greater awareness and more appropriate use of feedback strategies. A long-term workshop, that integrates specific objectives related to feedback strategies and reflection sessions interspersed with application work in the classroom, can promote participants' involvement, knowledge and skills in the use of these strategies. It can also result in greater involvement and learning by these teachers' students.

Keywords

Teacher education; Teacher feedback; Feedback strategies and effects; Workshop

\section{FEEDBACK EN LA PRÁCTICA DOCENTE: UN CURSO DE FORMACIÓN PARA EL PROFESORADO}

\section{Resumen}

El uso del feedback en el aula puede promover la calidad de las relaciones profesor-alumno, la participación académica y el rendimiento del alumnado, aunque los docentes no siempre lo usan de la mejor manera. En este artículo se describe el desarrollo y la evaluación de un curso diseñado para mejorar los conocimientos y capacidades de los docentes en el uso de estrategias de 
feedback, así como la valoración de las mismas. Doce profesores participaron en el curso. Historias y reflexiones del profesorado revelan que la participación en el curso potenció una mayor sensibilización y un uso más apropiado de las estrategias de feedback. Un curso de larga duración, que integre objetivos específicos relacionados con las estrategias de feedback y sesiones reflexivas intercaladas con el trabajo de aplicación en el aula, puede promover la participación, los conocimientos y las competencias de los participantes en el uso de dichas estrategias. También puede dar lugar a una mayor participación y aprendizaje por parte del alumnado del docente implicado.

\section{Palabras clave}

Formación para el profesorado; Feedback del profesorado; Estrategias y efectos del feedback; Curso de formación

Recebido em novembro/2014 Aceite para publicação em junho/2015

i Instituto de Educação, Unidade de Investigação e Desenvolvimento em Educação, Universidade de Lisboa, Portugal.

ii Instituto de Educação, Unidade de Investigação e Desenvolvimento em Educação, Universidade de Lisboa, Portugal.

iii Instituto de Educação, Unidade de Investigação e Desenvolvimento em Educação, Universidade de Lisboa, Portugal.

iv Instituto de Educação, Unidade de Investigação e Desenvolvimento em Educação, Universidade de Lisboa, Portugal.

v Faculdade de Ciências, Departamento de Educação, Universidade de Lisboa, Portugal.

vi Instituto Superior D. Afonso III, Loulé, Portugal.

vii Universidade Lusófona de Humanidades e Tecnologias, Lisboa, Portugal.

Toda a correspondência relativa a este artigo deve ser enviada para: Carolina Carvalho, Instituto de Educação, Universidade de Lisboa, Alameda da Universidade, 1649-013 Lisboa. E-mail: cfcarvalho@ie.ul.pt 